\title{
Seroprevalence of Dengue virus among pregnant mothers and their-newborn infants in the southwest of Saudi Arabia
}

\author{
Ali S. Alqahtani ${ }^{1, *}$ \\ ${ }^{1}$ Department of Medical Laboratory Sciences, Faculty of Applied Medical Sciences, Najran University, \\ Najran, 1988 (Kingdom of Saudi Arabia)
}

\begin{abstract}
Summary
Dengue virus (DENV) is one of the most serious arthropod-borne viruses. This study was performed to investigate the prevalence of the virus in Najran, a city in the south west of Saudi Arabia. Four hundred and ten paired maternal and umbilical serum samples were obtained from mothers and their newborn infants. The samples were tested for the presence of IgG antibodies by ELISA. Anti-DENV IgG antibodies were detected in 31 maternal samples (7.6\%), while all newborn samples were negative. All maternal seropositive samples were negative when tested by PCR. These results are further indication that DENV is endemic in Saudi Arabia and enhanced DENV surveillance is necessary.
\end{abstract}

Key words: Dengue; ELISA; PCR; Serum; Saudi Arabia; Pregnancy; Newborn infants.

\section{Introduction}

In recent decades, the incidence of dengue fever has increased dramatically in various parts of the world. Almost a fifth of the world's population is at risk of DENV infection. According to the World Health Organization, 50 million dengue infections occur every year worldwide [1-3]. Rapid movement of people, favorable climatic conditions and a lack of trained healthcare personnel have contributed to the global nature of dengue fever. The virus transmission occurs in about 128 countries and nearly 4 billion people are at risk [1-3]. DENV is a member of the family Flaviviridae, genus flavivirus. It causes a wide range of serious diseases, such as dengue fever (DF), dengue hemorrhagic fever (DHF) and dengue shock syndrome (DSS) [1-3]. The main vector of the disease is the mosquito, genus Aedes aegypti [4]. Dengue is transmitted by mosquito bites, so it spreads significantly after the rainy season in the summer [4].

Multiple outbreaks of different DENV serotypes were reported in Saudi Arabia since 1994. Dengue disease has become an endemic disease in different regions of Saudi Arabia, particularly in the western region [5-11]. The presence of Aedes aegypti, year-round travelling to perform Hajj, Omrah or for tourism, and direct contact with people from endemic areas are all putting the country at risk for these diseases. Little is known about the prevalence of DENV in the Najran area, in the south west of Saudi Arabia. In order to provide timely information about the disease, we have tested pregnant mothers and their newborns at the time of delivery in the city of Najran for subclinical or past infections of DENV.

\section{Material and Methods}

Study design

The study was done in the pediatric, gynecology and obstetrics hospital in Najran, in the period between November 2016 and July 2017. Four hundreds and ten pregnant women presenting at the hospital in labor, and who agreed to participate in the study, were enrolled in this crosssectional study. The study received ethical approval from the Research Committee of the College of Medicine, Najran University (approval number 15-01-18 EC).

\section{Questionnaire}

A questionnaire was administered to the patients covering information about place of residency, history of travel and any symptoms of illnesses.

\section{Sampling}

About five ml of clotted umbilical cord blood and maternal blood were collected from each participant. Blood samples were centrifuged at $3,000 \mathrm{rpm}$ for five minutes and sera were separated and preserved at $-60^{\circ} \mathrm{C}$ until being analyzed.

\section{ELISA}

DENV IgG were detected by ELISA. The kits were purchased from MyBioSource Inc., San Diego, USA. The test was performed in accordance with the instructions provided by the manufacturer.

\section{$R N A$ extraction}

Viral RNA was extracted from serum samples by TRIzol reagent (supplied by Thermofisher scientific company, USA) according to the user manual. DENV positive and 
Table 1. - Demographic and clinical characteristics of the mothers.

\begin{tabular}{lccc}
\hline Variables & & Total N (\%) & DENV IgG positive N (\%) \\
\hline Residency & In Najran & $342(83.4)$ & $29(8.5)$ \\
& Out of Najran & $68(16.6)$ & $2(2.9)$ \\
History of travel & Yes & $35(8.5)$ & $0(0)$ \\
& No & $375(91.5)$ & $31(8.3)$ \\
Temperature & 37 & $407(99.3)$ & $31(7.6)$ \\
& $>38^{\circ} \mathrm{C}$ & $3(0.7)$ & $0(0)$ \\
\hline
\end{tabular}

control extractions were performed and used alongside the experimental samples.

\section{$R T-P C R$}

The extracted RNA samples and positive and negative controls were mixed with Fast-track mastermix supplied by FTD dengue fast-track Diagnostics, Luxembourg. The samples were run on a LightCycler ${ }^{\circledR} 480$ (Roche) according to the instruction of the manufacturer.

\section{Data analysis}

The results of laboratory analyses of patient serum samples and the questionnaire data were analyzed by SPSS software version 23 (IBM). The differences among groups were identified using the chi-square test and the Pearson correlation coefficient.

\section{Results}

\section{Demographic and clinical characteristics of the mothers}

As shown in table 1, 35 of the mothers $(8.5 \%)$ had travelled inside Saudi Arabia before delivery but none of them had been abroad. Three hundred and forty two women $(83.4 \%)$ were from Najran city and sixty-eight $(16.6 \%)$ were from the surrounding villages. All mothers were asymptomatic except for $3(0.7 \%)$ who had a low-grade fever $\left(>38^{\circ} \mathrm{C}\right)$. All of the newborn babies showed normal growth parameters as per gestational age norms and none of them had congenital malformations.

\section{ELISA results}

Of the 410 tested maternal serum samples, 31 were positive $(7.6 \%)$ for DENV IgG. Of those, 29 samples were from residents of Najran city, while 2 samples were from residents of outside villages. A positive correlation between residency (Najran city) and maternal anti-DENV IgG was identified, with a non-significant $p$-value $(p=0.09)$. A significant negative correlation between a maternal history of travel and anti-DENV IgG was identified $(p=0.02)$. None of the febrile mothers had positive results (Table 1). All of the newborn samples tested negative for anti-DENV IgG.

\section{RT-PCR results}

The 31 maternal positive ELISA samples were subjected to RNA confirmation by RT-PCR. The PCR results showed that all samples were negative, indicating no active viral infection

\section{Discussion}

The presence of the DENV vector in Saudi Arabia represents a source of risk for DENV infection. The objectives of this study were to demonstrate the seroprevalence of DENV infection in the Najran region of Saudi Arabia and to identify the possible risk factors. Asymptomatic mothers and their newborn babies were screened for evidence of subclinical or past DENV infection. The major diagnostic methods for these virus outbreaks are serological tests, such as ELISA and viral RNA detection by RT-PCR [1217]. Therefore, both methods were used in this study to identify and confirm the infection. Our results indicated the presence of DENV in $7.6 \%$ in the tested samples. Although the results of this study agreed with previous research in Saudi Arabia in terms of the presence of the virus, the rate of infection was much lower than the previous rates. The published DENV prevalence in Saudi Arabia ranges from 14\% to $56 \%[7,9,10]$. The disease transmission can greatly differ from one region to another due to different factors such as vector density, methodological differences, the choice of study population, sample size, and other factors such as virus strain [18-20]. In our study, the demographic, clinical, and environmental factors did not have a significant association with the prevalence of the disease except for a higher prevalence of antibodies among non-travelers. Our results were in contrast to previous work in SA who indicated significant risk factors such as age $\geq 20$ years, lack of electricity and having water basins in the house [8].

Although there were no symptoms of active infection and viral RNA was not identified (confirming no active or asymptomatic infection), the presence of antibodies remains a significant concern. Transmission of DENV from asymptomatic or subclinical acutely infected blood donors to their recipients with subsequent disease development has been recorded [6, 21]. Moreover, transmission of antiDENV antibodies from donors enhances the viral infectivity in recipients who are later exposed to a different DENV serotype $[22,23]$. The findings in this study highlight the need for enhanced DENV surveillance, implementation of vector control strategies and determination of DENV serotype. 


\section{Acknowledgments}

I would like to thank all those who helped me during the writing of this manuscript and all the peer reviewers and editors for their opinions and suggestions.

\section{Conflict of Interest}

The authors declare no conflict of interest.

Submitted: Septemper 15, 2019

Accepted: November 07, 2019

Published: October 15, 2020

\section{References}

[1] Gubler D.J.: "The global emergence/resurgence of arboviral diseases as public health problems". Arch. Med. Res., 2002, 33, 330342.

[2] Ferguson N.M., Donnelly C.A., Anderson R.M.: "Transmission dynamics and epidemiology of dengue: insights from age-stratified sero-prevalence surveys". Philos. Trans. R. Soc. Lond. B Bio. Sci., 1999, 354, 757-768.

[3] Bhatt S., Gething P.W., Brady O.J., Messina J.P., Farlow A.W., Moyes C.L., et al.: "The global distribution and burden of dengue". Nature, 2013, 496, 504-507.

[4] Aziz A., Al-Shami S., Mahyoub J.A., Hatabbi M., Ahmad A., Rawi C.: "An update on the incidence of dengue gaining strength in Saudi Arabia and current control approaches for its vector mosquito". Parasites \& Vectors, 2014, 7, 258.

[5] Ashshi A.M.: "Serodetection of Dengue virus and its antibodies among blood donors in the western region of Saudi Arabia: a preliminary study". Blood Transfus., 2015, 13, 135-138.

[6] Azhar E., Kao M., Niedrig M., Masri B., Godus A., Badierah R. et al.: "Virological diagnosis of dengue fever in Jeddah, Saudi Arabia: comparison between RT-PCR and virus isolation in cell culture". Infect. Dis. Immun., 2010, 2, 24-29.

[7] Jamjoom G.A., Azhar E.I., Kao M.A., Radadi R.M.: "Seroepidemiology of asymptomatic Dengue virus infection in Jeddah, Saudi Arabia". Virology(Auckl), 2016, 7, VRT.S34187.

[8] Alhaeli A., Bahkali S., Ali A., Househ M.S. El-Metwally A.A.: "The epidemiology of Dengue fever in Saudi Arabia: A systematic review". J. Infect. Public Health, 2016, 9, 117-124.

[9] Al-Azraqi T.A., El Mekki A.A. Mahfouz A.A.: "Seroprevalence of dengue virus infection in Aseer and Jizan regions, Southwestern Saudi Arabia". Trans. R. Soc. Trop. Med. Hyg., 2013, 107, 368-371.

[10] Al-Raddadi R., Alwafi O., Shabouni O., Akbar N., Alkhalawi M., Ibrahim A., et al.: "Seroprevalence of dengue fever and the associated sociodemographic, clinical, and environmental factors in Makkah, Madinah, Jeddah, and Jizan, Kingdom of Saudi Arabia”. Acta. Trop., 2019, 189, 54-64.

[11] Ashshi A.M., Alghamdi S., El-Shemi A.G., Almdani S., Refaat B., Mohamed A., et al.: "Seroprevalence of asymptomatic dengue virus infection and its antibodies among healthy/eligible saudi blood donors: Findings from Holy Makkah City". Virol.: Research and Treatment, 2017, 8, 1178122X1769126.

[12] Gabor J.J., Schwarz N.G., Esen M., Kremsner P.G. Grobusch M.P.: "Dengue and chikungunya seroprevalence in Gabonese infants prior to major outbreaks in 2007 and 2010: A sero-epidemiological study". Travel Med. Infect. Dis., 2016, 14, 26-31.

[13] Lanciotti R.S., Calisher C.H., Gubler D.J., Chang G.J. Vorndam A.V.: "Rapid detection and typing of dengue viruses from clinical samples by using reverse transcriptase-polymerase chain reaction". J. Clin. Microbiol., 1992, 30, 545-551.

[14] Kuno G., Gómez I. and Gubler D. J.: “An ELISA procedure for the diagnosis of dengue infections". J. Virol. Methods, 1991, 33, 101113.

[15] Innis B.L., Suntayakorn S., Nimmannitya S., Hoke C.H., Chongswasdi V., Puttisri P., et al.: "An enzyme-linked immunosorbent assay to characterize dengue infections where dengue and Japanese encephalitis co-circulate". Am. J. Trop. Med. Hyg., 1989, 40, 418-427.

[16] Alcon S., Talarmin A., Debruyne M., Falconar A., Deubel V. Flamand M.: "Enzyme-linked immunosorbent assay specific to dengue virus type 1 nonstructural protein ns 1 reveals circulation of the antigen in the blood during the acute phase of disease in patients experiencing primary or secondary infections". J. Clin. Microbiol., 2002, 40, 376-381.

[17] Young P.R., Hilditch P. A., Bletchly C., Halloran W.: “An antigen capture enzyme-linked immunosorbent assay reveals high levels of the dengue virus protein ns 1 in the sera of infected patients". J. Clin. Microbiol., 2000, 38, 1053-1057.

[18] Guzmán M.G. and Kourí G.: "Advances in dengue diagnosis." Clin. Diagn. Lab. Immunol., 1996, 3, 621-627.

[19] Koraka P., Burghoorn-Maas C.P., Falconar A., Setiati T.E., Djamiatun K., Groen J., et al.: "Detection of immune-complexdissociated nonstructural-1 antigen in patients with acute dengue virus infections". J. Clin. Microbiol., 2003, 41, 4154-4159.

[20] Fritzell C., Rousset D., Adde A., Kazanji M., Van Kerkhove M.D., Flamand C.: "Current challenges and implications for dengue, chikungunya and Zika seroprevalence studies worldwide: A scoping review". Plos Negl. Trop. Dis., 2018, 12, e0006533.

[21] Wilder-Smith A., Chen L.H., Massad E. Wilson M.E.: "Threat of dengue to blood safety in dengue-endemic countries". Emerg. Infect. Dis., 2009, 15, 8-11.

[22] Ribas-Silva R.C. Eid A.A.: "Dengue antibodies in blood donors". Rev. Bra. De Hematol. Hemoter., 2012, 34, 193-195.

[23] Mangwana S.: "Dengue viremia in blood donors in Northern India: Challenges of emerging dengue outbreaks to blood transfusion safety". Asian J. Transfus. Sci., 2015, 9, 177.

Corresponding Author:

ALI SAEED ALQAHTANI

Department of medical laboratory sciences,

Faculty of applied medical sciences, Najran University,

Najran, 1988 (Kingdom of Saudi Arabia)

e-mail: almezherali@gmail.com 